\title{
DEPENDENCE OF STAFF EFFICIENCY ON STRESS IN THE WORKPLACE
}

\section{Tetiana Obelets ${ }^{1}$}

\author{
DOI: https://doi.org/10.30525/978-9934-588-11-2_68
}

Stress in the workplace, ranked by the International Health Organization as one of the major disease of the 21 st century, was the subject of a report by the International Labour Organization in 2016. Globalization and technological progress are changing both the enterprises themselves and the relationships that arise in the process of economic activity. The global financial and economic crisis of 2008-2009 has led to increased poverty and unemployment. In 2009, global GDP fell by 2.3 per cent and the unemployment rate reached 199 million people. As a result, to remain competitive, many enterprises have moved to optimization measures: restructuring, mergers, outsourcing and contracting, and mass layoffs. These are all factors that, together with others, contribute to the stress of workers. In addition, the occurrence of stress, in turn, affects the economic performance of the company. Several professional organizations are engaged in studying the problem of workplace stress in the world: World Health Organization, The American Institute of Stress, American Psychological Association, etc. In Ukraine, the problem of stress at the workplace has several characteristic features: inadequate to the efforts and time spent on wages, unstable forms of employment, inconsistency of work and skills or knowledge, overtime work, unstable political and economic situation as a result of hostilities in the East of Ukraine, a large outflow of specialists abroad, the lack of a state approach to solving this problem. That is why the uncertain economic losses from the stress of Ukraine's weakened economy further slow down its growth rate. Thus, stress studies from an economic point of view are necessary to create favourable conditions for economic growth.

Any man's life is impossible without stress. Stress is part of our daily experience. In North and South America, according to the 1st Central American Health and Safety Survey, each of the ten workers is continuously experiencing severe stress $12-16 \%$, depression $-9-13 \%$, loss of sleep $-13-19 \%$ of the causes related to working conditions. According to the statistics on injuries and occupational diseases, $14 \%$ of the financial assistance for disability in Brazil was due to mental illness, of which $9 \%$ were for men and $16.7 \%$ for women. Concerning the work-life balance survey, $57 \%$ of workers in Canada have experienced high levels of stress in recent years, compared to $54 \%$ in 2001 and $44 \%$ in 1991 [1]. At the same time, 36 per cent of workers were depressed, 31 per cent had reduced sleeping time, and 46 per cent felt physically unwell. At the same time, the number of people who are satisfied with their lives has decreased from $45 \%$ in 1991 to $23 \%$. Finally, no more than $75 \%$ of workers were absent from work in the 6 months before the survey, mainly due to

\footnotetext{
${ }^{1}$ National Technical University of Ukraine «Igor Sikorsky Kyiv Polytechnic Institute», Ukraine
} 
illness $-63 \%$ and emotional, psychological and physical fatigue $-45 \%$. In Chile, stress and depression were reported by $27.9 \%$ of employees and $13.8 \%$ of employers. In addition, according to the Occupational Safety and Health Association, 21 per cent of the 4,059 occupational diseases in the country in 2012 were related to mental disorders. In the United States, according to a stress survey in 2015, the most common sources of stress were money $-64 \%$, work $-60 \%$, the economy $-49 \%$, family responsibilities $-47 \%$ and concern about their health $-46 \%$ [2]. The data provided here illustrates the spread of stress in the world and its relationship to various mental and physical illnesses.

In European countries, most of the data are provided by EU organizations. According to the results of the EWCS survey of working conditions, stress at work is observed in 40,000,000 workers, which results in 50\%-60\% of working time losses, and the level of stress also depends on the main economic indicators, to which the Human Development Index and GDP per capita are known to belong. Thus, stress in the countries that joined the EU later on, Romania - GDP $=\$ 10757$, HDI $=0.811$, Croatia $-\$ 13138$, HDI $=0.831$, Bulgaria - GDP $=\$ 8064$, HDI $=0.813$ is felt by an average of $30 \%$ of workers, while for the old EU member states of Luxembourg, GDP $=\$ 105803$, HDI $=0.904$, Switzerland $=\$ 80590$, HDI $=0.944$, Norway $=$ $\$ 74940$, HDI $=0.953-20 \%$. In these countries, about $23 \%$ of accidents are due to stress. In Ukraine, GDP $=\$ 2582$. HDI $=0.813$, then $70 \%$ of the Ukrainian population is under stress and one-third of the population is under severe stress [3]. In general, having reliable data on stress, determined by the same methodology of conditions, it is possible to construct a regressive dependence of working time losses, or the level of stress depending on GDP per capita and human development index. The stress indicator can be used to predict economic parameters, such as labour productivity.

At more than $\$ 120,000,000,000$ per year, U.S. scientists have estimated the costs associated with the effects of stress on human health. This figure includes the effects of stress, such as reduced productivity, reduced working hours, and the cost of treating large numbers of nervous stress-related illnesses.

Thus, a comprehensive approach to addressing the impact of stress on economic efficiency is needed today, combining the assessment of the level of stress, the prediction of economic indicators and the creation of effective means of preventing it.

\section{References:}

1. Workplace stress: A collective challenge. ILO Publications (Rights and Licensing), International Labour Office, CH-1211 Geneva 22, Switzerland.

2. URL: http://www.ilo.org

3. URL: Statystyka stresu, [Online]. Available at: http://www.lossofsoul.com/STRESS/ statistics-ua.htm

4. URL: http://www.who.int/mental_health/in_the_workplace 